\title{
THE CALCULATION OF HORIZONTAL ACCELERATIONS FROM SEISMOSCOPE RECORDS
}

\author{
By RoNald F. SCOTT
}

\begin{abstract}
The seismoscope is a simple instrument designed originally to give a largely qualitative indication of the strong ground motions produced by an earthquake. It consists of a smoked watch glass attached to a two-degree-of-freedom pendulum with a period of $\frac{3}{4}$ sec and damping about 10 per cent of critical; a pen records the pendulum motions on the watch glass. One point on the displacement spectrum of the recorded ground motion at this period and damping is obtained from the measurement of the maximum pendulum excursion.

An examination of the seismoscope record obtained on the east abutment of the failed Lower San Fernando dam during the 1971 San Fernando earthquake showed a high-frequency vibration superimposed on the general oscillations. It did not seem likely that this was solely an earthquake vibration component, and shaking table tests of seismoscopes revealed the presence of a seismoscope vibration mode at frequencies of 15 to $18 \mathrm{~Hz}$ depending on the instrument. The oscillations due to this mode on the abutment seismocope record have, therefore, been used as timing marks, to enable the seismoscope equation to be solved for the input acceleration components. The results of the calculations are presented along with analyses of the seismoscope response to indicate the range of applicability. One other record, obtained on a seismoscope alongside a strong-motion accelerograph, was also analyzed for comparison with the recorded accelerations, to demonstrate the validity of the technique. The timing vibration appears on a number of seismoscope records.
\end{abstract}

\section{INTRODUCTION}

The San Fernando earthquake of February 9, 1971 was recorded by more strongmotion accelerometers than have recorded any previous earthquake (Hudson, 1971). In addition to the strong-motion acceleration recording devices, many seismoscopes also recorded the earthquake at a variety of locations. The seismoscope, which was designed by the U.S. Coast and Geodetic Survey about 12 years ago (Cloud and Hudson, 1961), consists of a pendulum to which is attached a smoked watch glass. A pen writing on the watch glass records the motion of the pendulum during shaking by an earthquake. The original intention behind the seismoscope was to provide an inexpensive means by which the ground motion in an earthquake would be qualitatively indicated. In addition, measurement of the maximum excursion of the pendulum enables one point on the displacement spectrum to be established at the period and damping of the instrument. The seismoscope was designed to have a period of about $\frac{3}{4} \mathrm{sec}$ and damping of about 10 per cent of critical. Many seismoscope records have been obtained (Cloud and Hudson, 1968; Hudson, 1971). One seismoscope record, located near an accelerometer in which one horizontal component was lost through a malfunction, was used in an analysis to reconstruct the lost component (Trifunac and Hudson, 1970).

In the San Fernando earthquake, a strong-motion accelerometer recorded very strong motions at the site of Pacoima dam, approximately 5 miles from the epicenter. The next nearest recording accelerometer was located 9 miles farther away in the Holiday Inn at 
8244 Orion Boulevard in the San Fernando Valley. However, much damage was caused by the earthquake in Sylmar and northern parts of the San Fernando Valley, where no strong-motion accelerometers existed. Both the damaged San Fernando dams were located in this area and, considering the massive failure of the upstream slope of the lower dam (Jennings, 1971), the lack of a record of the input motions is unfortunate. The lower

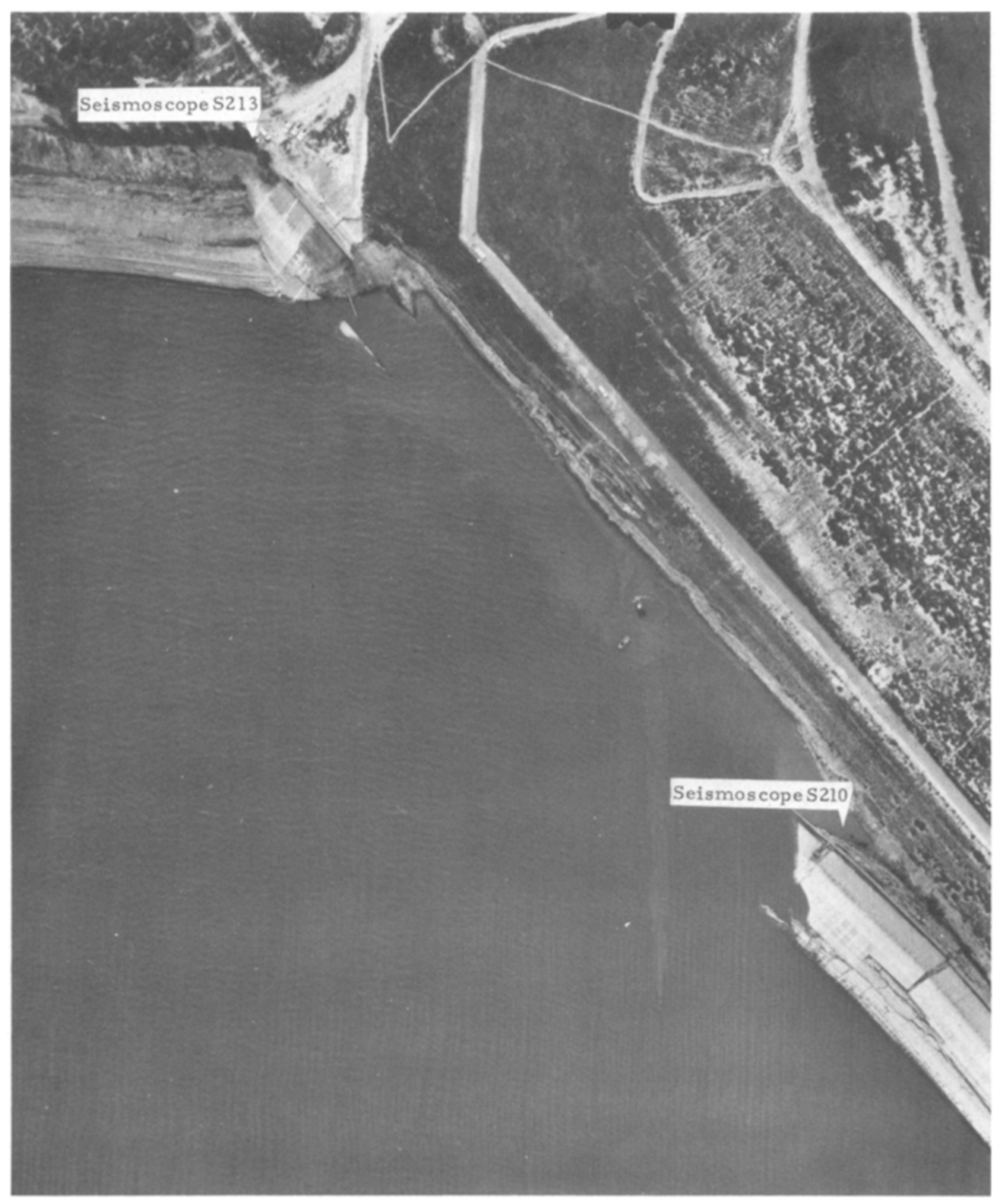

FIG. 1. Seismoscope locations at Lower San Fernando Dam.

dam is 10 miles from the epicenter. Substantial damage was also undergone by the upper San Fernando dam. A satisfactory analysis of the dam's behavior is difficult without information on the ground motion.

However, at the lower San Fernando dam, a seismoscope (S-210) and a peak recording accelerometer (Hudson, 1971) were located on the crest and another seismoscope, S-213, 
was positioned on the sandstone sedimentary bedrock forming the east abutment (see Figure 1). Both of these instruments recorded the shaking during the earthquake, and the seismoscope on the crest of the dam subsided, with the failure of the upstream slope, below the level of the reservoir. Consequently, the record from that seismoscope could not be retrieved for several days following the earthquake until the water level had been sufficiently lowered. As a fortunate consequence of the design of the seismoscope casing, air was trapped underneath the dome of the casing so that the smoked seismoscope record survived intact. Figure 2 shows the location of the seismoscope on the crest following the failure after the reservoir level had been lowered. From the water mark on the outside of the case it was determined that the seismoscope had been tilted through $37^{\circ}$ during the failure (Hudson, 1971). Figure 3 shows the location of the seismoscope on the east abutment.

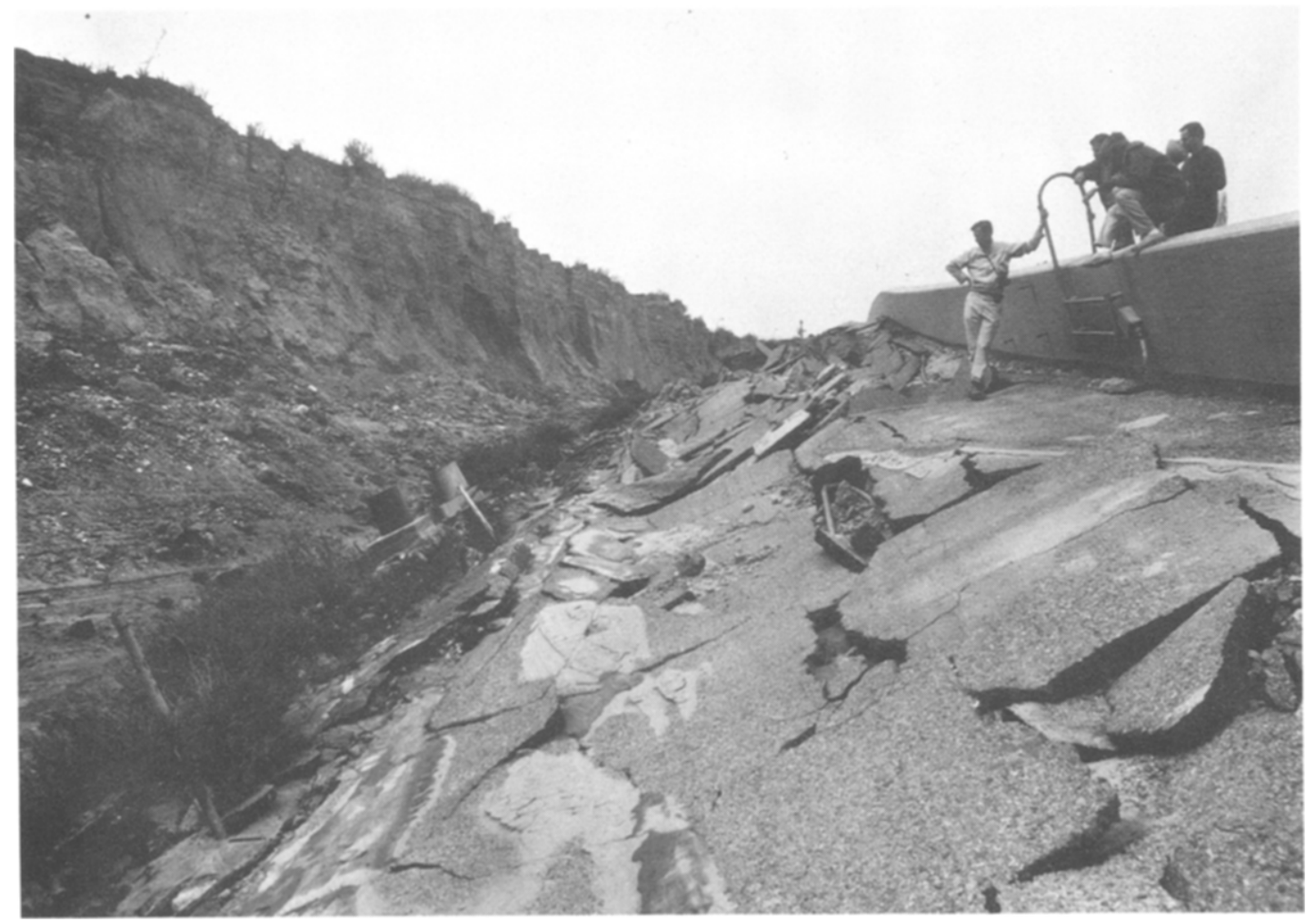

FIG. 2. Photograph of post-earthquake position of crest seismoscope (S-210).

When the two watch glasses were retrieved, it was found that they retained excellent traces of very strong motion recorded during the earthquake (Hudson, 1971). Figure 4, a and $b$ shows the two records. It may be noted that there was also a seismoscope on the crest of Pacoima dam, but the watch glass on that instrument came off the pendulum during the violent motion, so that it shows only a small portion of the movement that occurred.

While preparing a section of a preliminary report on the earthquake, the author examined the seismoscope records from the lower San Fernando dam in order to calculate the spectrum values for the two instruments at these locations as a guide to the performance of the dam. These measurements were made and reported (Jennings, 1971). It was obvious, as can be seen from Figure 4, that the two records, whose amplitudes are similar, are somewhat different in detail. As an accident of the condition of the pen needle and the 
smoking of the record, the seismoscope on the east abutment gave a much clearer and finer trace than the one on the dam itself. In addition to this, it can be seen that there is a high-frequency oscillation superimposed on the abutment record; this is lacking, in general, from the record obtained on the crest. However, a careful scrutiny of the latter shows that there are high-frequency oscillations on certain portions of that record too.

At first, it was supposed that this high-frequency oscillation represented the contribution of a high-frequency component of the earthquake. To determine the frequency, the number of cycles of the higher-frequency oscillation between the peaks of the major swings of the seismoscope was counted. In its normal mode of operation, the seismoscope swings at almost its natural period between peaks that are connected by fairly smooth curves, and, consequently, it is possible to approximate the timing of these peaks. When

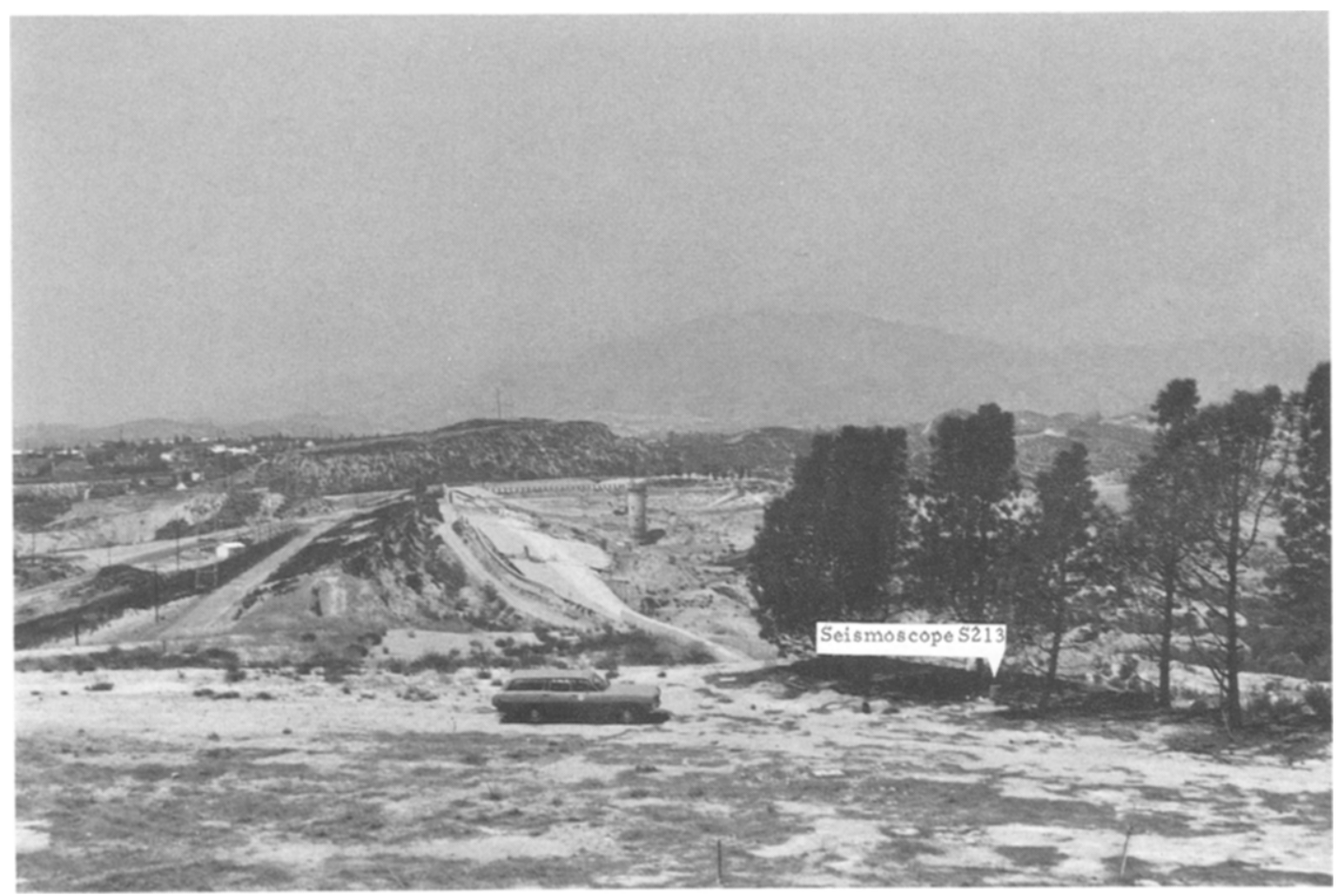

FIG. 3. Photograph of position of east abutment seismoscope (S-213).

this was done it was found that there were six or seven cycles of higher frequency oscillation between numbers of pairs of peaks, regardless of the amplitude of the swings. This seemed to be more than coincidence, and it was suspected that the higher-frequency oscillations might be an instrument characteristic rather than due to the earthquake. Accordingly, a seismoscope in the Earthquake Engineering Laboratory at the California Institute of Technology was placed on a shaking table and its response studied over a range of frequencies. It was found that at a frequency of about 16 to $18 \mathrm{~Hz}$, depending on the instrument characteristics and at input acceleration amplitudes of less than a few per cent of gravity, the pendulum vibrated in resonance with the superimposed oscillation. When the pendulum was given a large displacement while this oscillation was occurring, it was found that the trace had an appearance very similar to portions of the abutment record. For the actual abutment seismoscope S-213 the characteristic frequency was measured to be $16.5 \mathrm{~Hz}$. The instrument damping in this mode is quite small. 

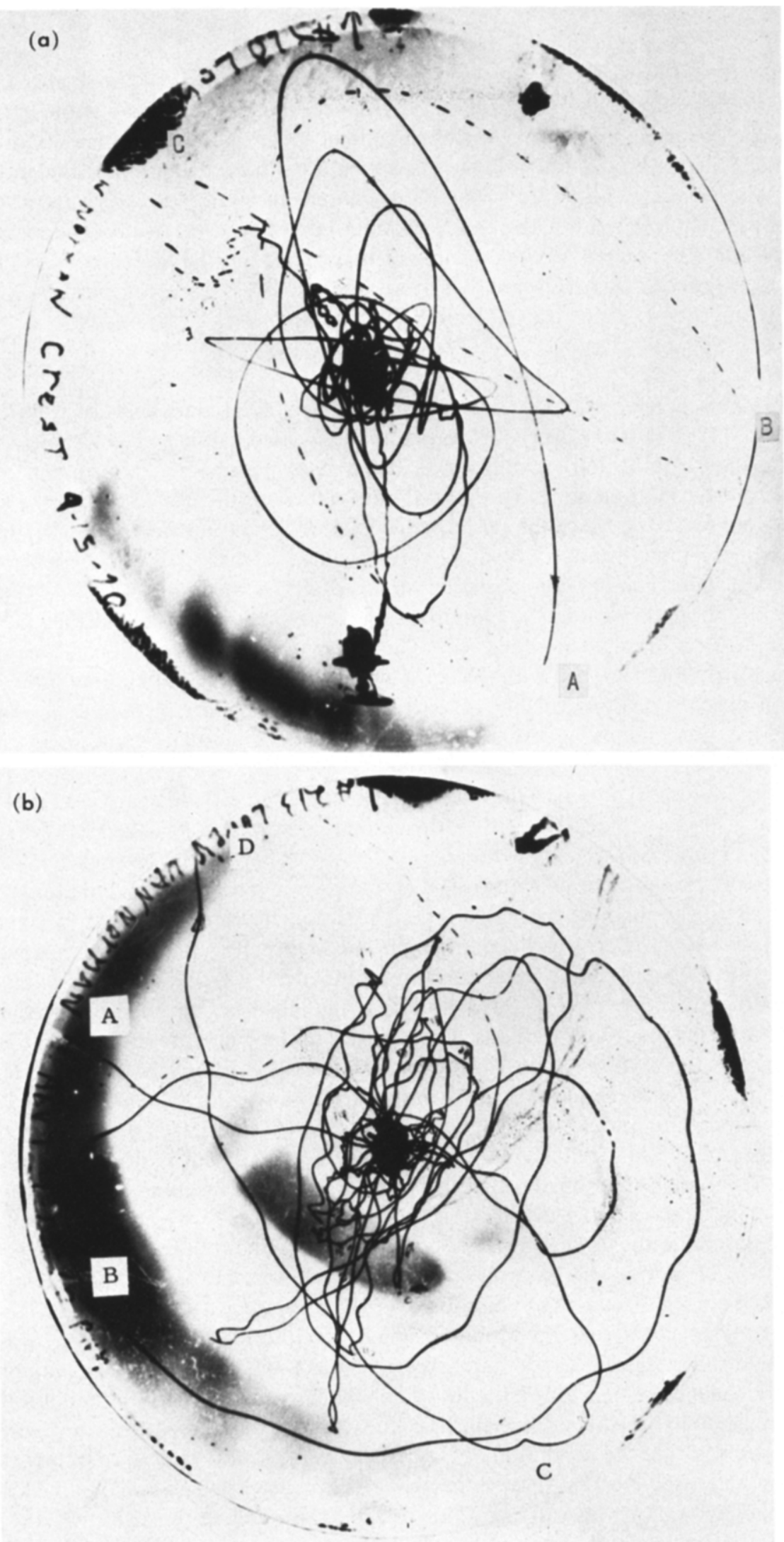

Fig. 4. Seismoscope records from earthquake of February 9, 1971 : (a) crest, S-210, and (b) abutment, S-213. 
This very fortunate occurrence immediately suggested that the higher-frequency oscillations could be used as a timing mark superimposed on the rest of the trace. Then, since the equations of motion of the seismoscope were known, the measured displacements of the trace on the watch glass could be used in a calculation of the acceleration components which excited the seismoscope and produced the trace. This paper describes the subsequent analyses of the San Fernando dam abutment seismoscope record S-213 and of one other record, obtained adjacent to a strong-motion recording instrument, for the purpose of calibrating the analysis procedure.

\section{ANALYSIS}

A seismoscope record has previously been analyzed to give acceierations (Trifunac and Hudson, 1970). In that case, the seismoscope was located beside an accelerometer, both of which recorded the Parkfield earthquake in 1966. However, one component of the accelerometer malfunctioned so that only the vibrations at right angles to the causative fault were recorded. Since the seismoscope recorded the complete motions of the earthquake at the same location, it was used to calculate a few seconds of the motion in the other direction. The one component of measured acceleration was used with the seismoscope equation to calculate the motion which the seismoscope would display in the same direction. From the seismoscope record, the component of its motion in this direction was obtained and matched with the computed motion in order to obtain a time scale for the seismoscope record. Thus the other component of the motion could then be analyzed using the seismoscope equation to give a calculated input acceleration in the other component direction.

It is of interest to note that the high-frequency oscillations which are used in this paper as timing marks are also present in the seismoscope record analyzed by Trifunac and Hudson. Their analysis included these oscillations as part of the seismoscope pendulum (first mode) response to the earthquake, so that they were led to conclude that one component of the earthquake contained more high-frequency oscillations, at $15 \mathrm{~Hz}$, than the other. Because of relatively low damping in the higher mode, the high-frequency vibrations can continue for some time after being stimulated by a sudden motion of the seismoscope. The direction of the $15 \mathrm{~Hz}$ vibrations may also be mechanically related to the direction of the first-mode motions. The presence of the higher frequency in the Parkfield record may, therefore, be a consequence of only one or two impulsive input accelerations.

The pendulum of the seismoscope is suspended by a small wire filament approximately 0.3 in in length and 0.015 in in diameter. It was this suspension that permitted the highfrequency oscillation characteristic of the instrument to occur. A drawing of the instrument is shown in Figure 5 in which the mode of vibration resulting from the bending of the wire filament is shown. For input acceleration amplitudes of a few per cent of gravity, the amplitude of the oscillations of the watch glass is about 0.05 to $0.07 \mathrm{in}$, whereas the amplitude of motion of the damper plate at the lower end of the instrument is much smaller. This high-frequency oscillation can be generated by a sudden shock to the instrument or by an earthquake excitation of sufficient amplitude at this frequency. At the east abutment of the San Fernando dam, the earthquake may have contained enough energy at the frequency of $16.5 \mathrm{~Hz}$ characteristic of the instrument there to maintain the highfrequency oscillation through a majority of the record. Alternatively, since an experimental study showed that the pendulum of the instrument struck its support a number of times during the strong motion, these impacts may have generated and maintained the highfrequency vibration. The construction of the seismoscope is such that the normal stationary position of the pen before and after the earthquake is in the center of the watch glass. 
The proper evaluation of the accelerations recorded at a particular site requires that the direction of movement of the pen in time be known, and this is not evident in a record obtained by seismoscope in a standard way. However, in both the records shown in Figure 4, the motion of the seismoscope pendulum was violent enough that the pen left the watch glass at points A, B and C in Figure 4a, and at A and D in Figure 4b, returning to the record again at nearby points. The pen on the seismoscope is quite delicately balanced so that it can be concluded, and confirmed by experiment, that the pen, while recording a smooth trace as it leaves the watch glass, will, on coming back onto the glass again, execute a series of skips or jumps. The skips or jumps may be aggravated by vertical accelerations. It appears that the direction of time can be determined on a particular trace to be increasing in the direction in which the pen goes off the record as a smooth trace and comes back as a dotted one. When this consideration is applied to both

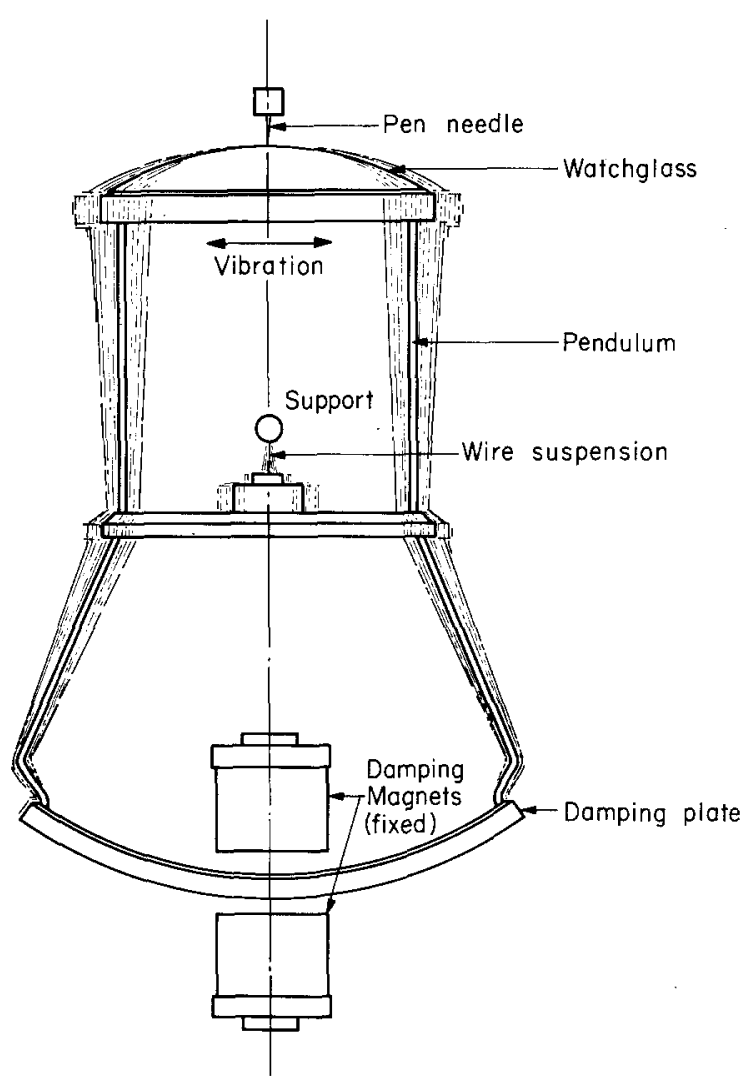

FIG. 5. High-frequency mode of oscillation of seismoscope.

(a) and (b) of Figure 4, it can be seen that the various places where the pen leaves the record give a consistent indication of the direction of flow of time. In the photographic enlargements which were produced for the analysis, the overlapping of successive tracings can frequently be distinguished. In the present case, these merely confirmed the results, but in analyses of records confined entirely to the watch glass, examinations of overlaps would be necessary for determining the direction of time.

The equation of motion governing the seismoscope behavior in the two component directions is (Trifunac and Hudson. 1970)

$$
\ddot{\phi}+\frac{4 \pi n}{T} \dot{\phi}+\frac{4 \pi^{2}}{T^{2}} \phi=-\frac{4 \pi^{2}}{T^{2} g} \ddot{x}(t)
$$


where

$\phi$ is the angle of displacement of the pendulum in the component direction,

$T$ is the period of the pendulum,

$n$ is the damping, expressed as a proportion of critical,

$g$ is the acceleration of gravity, and

$\ddot{x}(t)$ is the input acceleration in the component direction

The same equation, with the same instrument constants, but with $\psi$ and $\ddot{y}(t)$ replacing $\phi$ and $\ddot{x}(t)$ describes the pendulum motion in the other component direction. The effect of vertical accelerations on the pendulum motion has been examined and found to be small (Cloud and Hudson, 1961 ; Trifunac and Hudson, 1970).

Because the damping of the seismoscope is a combination of the friction of the needle on the glass record and the magnetic damping of the lower plate, it is not constant. Instead, the amount of damping on any particular swing of the pendulum varies with the maximum displacement occurring on the swing. Damping typically varies from a maximum of 12 or 13 per cent of critical for small oscillations to 6 or 8 per cent of critical on the larger oscillations of the instrument. An experimental calibration of the damping on each instrument is carried out periodically.

The Cartesian coordinates of a point on the seismoscope record in a photograph of the record, such as in Figure 4, a or b, can be related through the instrument geometry to the two angles, $\phi$ and $\psi$. Thus, measurement of the spatial and time coordinates of points along a trace on the glass surface enables the accelerations $\ddot{x}(t)$ and $\ddot{y}(t)$ to be calculated from equation (1). Use of the timing oscillation described above permits this to be done.

The processing of the record requires a number of steps which will now be discussed. These apply in particular to the record from the abutment seismoscope S-213.

First of all, the record must be disentangled or unraveled in order to follow the trace as it was generated during the earthquakes. At present, this seems to be the biggest obstacle to analyzing a number of seismoscope records. The abutment seismoscope record, because of its size and nature, is relatively easy to disentangle. However, even on this record a large number of traces pass through the center of the watch glass and tend to obscure the smaller amplitudes of vibration before and after the strong motion. In order to facilitate the disentangling, the original seismoscope watch glass was used as a negative in a photographic enlarger to produce positive prints at a range of magnifications. One enlargement of the whole record at a magnification of about 8 was used as the master print for analysis. Other enlargements of the central portion of the record were made at magnifications of 20 to 40 so that individual lines could be followed where they passed near the center. Experiments were carried out with different exposure times and photographic paper of different contrasts in order to determine the best combination for clarifcation of the record. A surprising amount of detail becomes apparent by this method. A photograph of a portion of the record is shown in Figure 6. The unraveling of the sequence of events was traced by colored pencils on a plastic overlay on the 8-times enlargement of the record. When this process was completed for record S-213, it had been found possible to disentangle about $15 \mathrm{sec}$ of the record including all of the strongmotion portion which was approximately $10 \mathrm{sec}$ in length. In the course of the disentanglement, stretches of record were found in which the trace could be clearly followed over a number of swings. In other places, the line could not be clearly distinguished over a short distance, always in the confused central area. As a consequence of this, the eventually unraveled trace of S-213 consists of three well-determined portions separated by two short stretches in which the location of the line can be determined only approximately. The first 
portion of trace to be disentangled consists of intermediate-sized loops, giving a record a few seconds long. The second section comprises about $10 \mathrm{sec}$ of clearly distinguishable and unambiguous strong motion, and the third section again consists of loops of medium size, along which the trace is again relatively well defined. These three sections are joined as well as the trace can be followed in the central area. The junction depends on the observer and it is entirely possible that the well-defined portions of the trace are connected incorrectly. Thus the two regions of smaller motion, perhaps 2 or $3 \mathrm{sec}$ long, may be located erroneously with respect to the strong motion. It is not thought that this would affect either the calculated spectra nor the use of the derived strong-motion acceleration

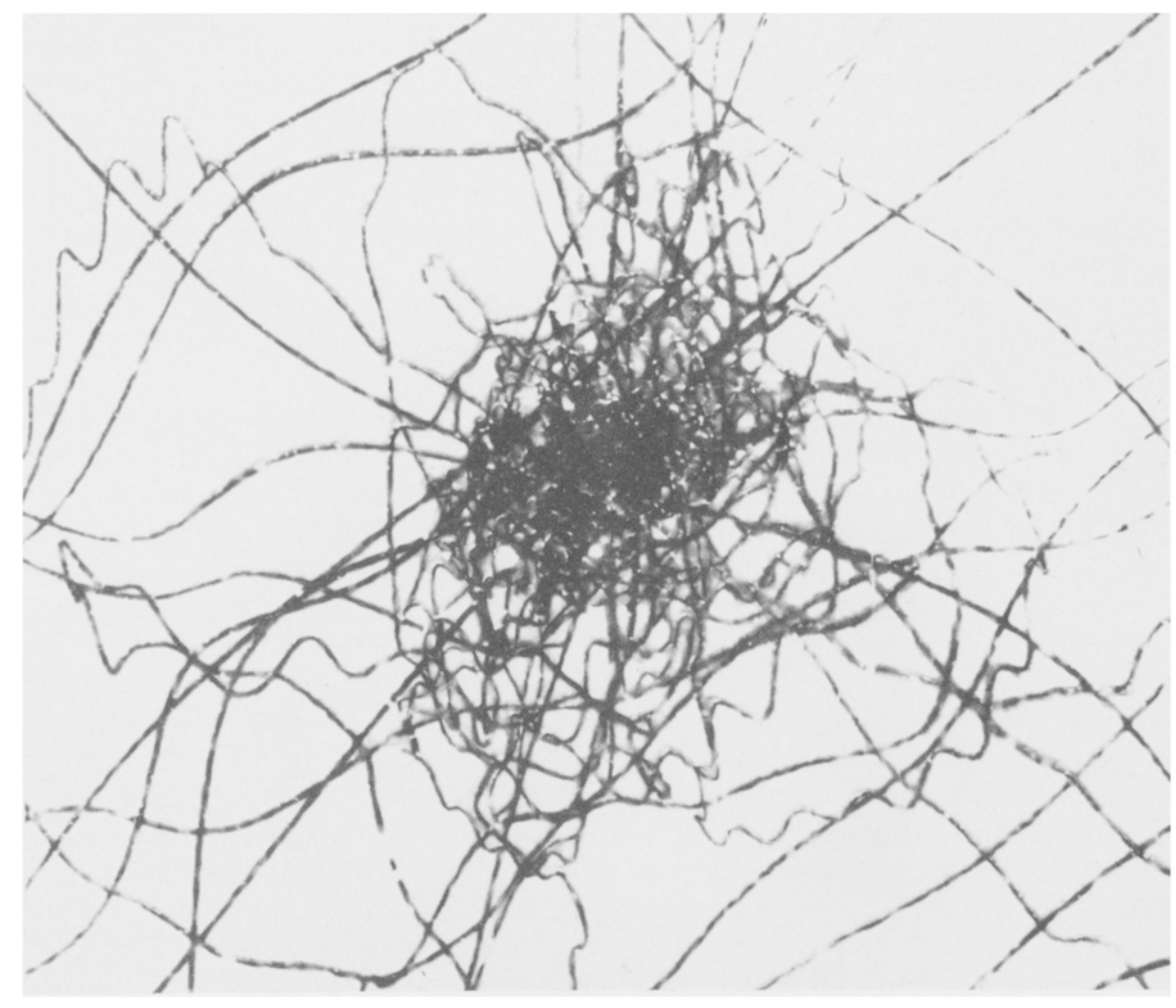

FIG. 6. Enlargement of central portion of S-213 record.

record for any interpretive purposes. It is emphasized that the section of most vigorous motions is clearly unambiguous; it has been examined by several observers, with no disagreement.

Since the work of disentangling is carried out on a flat surface obtained plotographically, it was necessary to make an adjustment for the scale change from the original spherical surface of the watch glass to the plane surface of the photograph. This was done by marking a smoked seismoscope watch glass with a series of scratches to provide a scale and then producing an enlargement of this record to the same magnification as the record to be analyzed. Measurements from the enlargement resulted in a calibration curve which was used in the subsequent calculations.

The next stage in the calculation process was to digitize the disentangled record on a Benson-Lehner digitizer at the Earthquake Engineering Research Laboratory at Caltech. 
This was done in two stages. First of all, the enlargement $(\times 8)$ of the original record was placed on the digitizer, centered, aligned, and then a sufficient number of points was digitized ( $x$ - and $y$-coordinates) to define adequately the loops and timing oscillations along the disentangled portion. This gave a deck of computer cards with the spatial coordinates of all points on the disentangled record. These were used in a computer program which plotted the resulting trace as a precaution against mistakes or digitizer malfunctions. No times were known at this stage. For the acceleration calculations it was necessary to determine the smooth curve that would have described the seismoscope trace if the $16.5 \mathrm{~Hz}$ oscillation were not present. The points of intersection of the smoothed line with the timing oscillations would then occur at known time intervals along the trace. Ideally, this fitting should be done by computer and, in fact, a variety of ways of accomplishing it were investigated. In the time available, no convenient method was found to fit automatically the variety of loops and sharp curves represented by the seismoscope record. It was decided that the most expeditious method of carrying out the work was to smooth each individual portion of the trace by hand, and to fit by eye the intersections of the smooth curve with the oscillatory real curve. However, it was found too confusing to work with the trace when the entire disentangled seismoscope record was prepared on one piece of paper. Accordingly, the digitized record was reproduced in a series of segments of the record, each one consisting of a suitably enlarged portion of the trace about 50 digitized points long.

When the smoothing was done, the intersections with the real curve gave timing intervals at one-half the period of the oscillations apart. In addition, a further timing mark was placed between these points from the location of the maximum or minimum of the oscillation above or below the smoothed line. In this way, coordinates of the seismoscope trace at equal time intervals corresponding to one-quarter of the period of the vibrations of the instrument were obtained. For the higher-mode natural frequency of the S-213 seismoscope, these timing marks were $\frac{1}{66} \mathrm{sec}$ apart. At the next stage, the plots were returned to the digitizer and a fresh set of coordinates generated by digitizing the points which had been marked at the equal time intervals. This process gave a deck of cards representing a smoothed seismoscope record digitized at equal time intervals; this was the basic data deck to be used for analysis.

The problem of calculating first and second derivatives from numerical data consisting of spatial coordinates at known times is well known. Small errors in the coordinates give rise to large errors in the calculated acceleration (Lanczos, 1961). The proportion of the acceleration derived from each of the three terms on the left side in equation (1) depends on the frequency of the forcing acceleration. At frequencies lower than the seismoscope frequency, the seismoscope acts as an accelerometer, and the calculated acceleration derives mostly from the displacement term alone, which is quite accurately determined. At frequencies higher than its natural frequency, the seismoscope tends toward a displacement meter, and the calculated accelerations arise from the acceleration term on the left-hand side. Because of the two differentiations involved, the calculated accelerations at high frequencies will be less accurate.

An approximate analysis of the behavior of the instrument and the degree of discrimination involved in digitizing and smoothing was performed. This indicated that longerperiod (up to several seconds) accelerations of amplitudes greater than about $0.002 \mathrm{~g}$ could be discerned on the record, providing these were superimposed on the general swings of the pendulum, since the damping is small at large displacements. High-frequency input vibrations, on the other hand, had to occur at larger acceleration amplitudes to be discernible on the trace. The analysis indicated that these amplitudes should be greater than about $0.05 \mathrm{~g}$, at a frequency of $10 \mathrm{~Hz}$, for the seismoscope pendulum to respond to them, although smaller accelerations than this at $16.5 \mathrm{~Hz}$ would excite the high- 
frequency timing mode of vibration of the instrument. The analysis indicated that some smoothing was required, and it was decided that a high-frequency cutoff digital filter due to Ormsby (1961) would be employed, although a Fourier series representation was also examined. An Ormsby filter operates by calculation of suitable weighting factors for a number of points, to accomplish filtering at selected frequencies. The first stage in the data analysis, therefore, consisted of smoothing the digitized data with an Ormsby filter to a roll-off frequency of $10 \mathrm{~Hz}$ and a cutoff frequency of $12.5 \mathrm{~Hz}$. The data were then differentiated numerically and the component accelerations calculated by computer from equation (1) using the measured characteristics of the instrument.

In an extended numerical process like this, a number of errors can be made, and it is desirable to institute procedures to check for them. The technique adopted for the present calculations was, first, to make the computer plot the original as well as the smoothed input data. These can be compared with the original seismoscope record to make sure that no gross errors in the digitization or smoothing processes had been made. Next, the component accelerations were calculated, plotted, and punched on cards. Following this, the integrated velocities and displacements of the two components were calculated as an indication of the error in the location of the instrument center. Since equation (1) can also be used to compute the seismoscope response from given input accelerations, it was decided to use the calculated accelerations in a further computation of the seismoscope response to compare with the original seismoscope record as a final check.

Although an approximate error analysis of the calculational techniques was done, it was considered more instructive to carry out an acceleration calculation based on a seismoscope record which had been obtained next to a recording accelerometer for a comparison between the calculated and measured accelerations. To do this, three conditions were necessary: (1) the seismoscope record be located next to an accelerometer; (2) the record be in an area of fairly high accelerations so that a large amplitude seismoscope record would be available for analysis; and (3) the seismoscope record contain highfrequency oscillations. It was also desirable that the record be suitable for unraveling; this requires a record in an area of isotropic accelerations, so that the traces intersect at large angles. Not many records satisfy these conditions, and only two were found suitable for further scrutiny; the Castaic Old Ridge Route seismoscope and acceleration record, and the California Institute of Technology Athenaeum seismoscope and acceleration record (Hudson, 1971). Both of these meet the general requirements above, although the Athenaeum record is somewhat smaller since it was farther away from the epicenter of the earthquake. In addition, the Castaic record is essentially a uni-directional record, so that many of the traces of the seismoscope needle cross each other at very small angles to make disentangling of the record difficult. However, since it was the bigger record of the two with fairly well-defined timing oscillations, it was selected for analysis first.

When the work was begun, it was decided, for reasons of objectivity, not to examine the measured acceleration record until the analysis was complete. Even with a fair effort, it proved possible only to unravel about $3 \mathrm{sec}$ of the Castaic record in a satisfactory way. When the accelerations had been calculated, the measured acceleration records were obtained for comparison. It was immediately obvious, on examination of the measured acceleration records, that the accelerometer had malfunctioned and the recording paper had, in fact, stopped during a portion of the strong motion of the earthquake. It is estimated that in a total estimated duration of strong motion of several seconds the instrument had been stopped for at least a second or two and had recorded only about $3 \mathrm{sec}$ of strong motion. When a comparison was attempted, it was not possible to identify the calculated accelerations with the recorded portion of the strong motions at the Castaic instrument. This analysis was therefore terminated, and attention was turned to the Athenaeum record. 

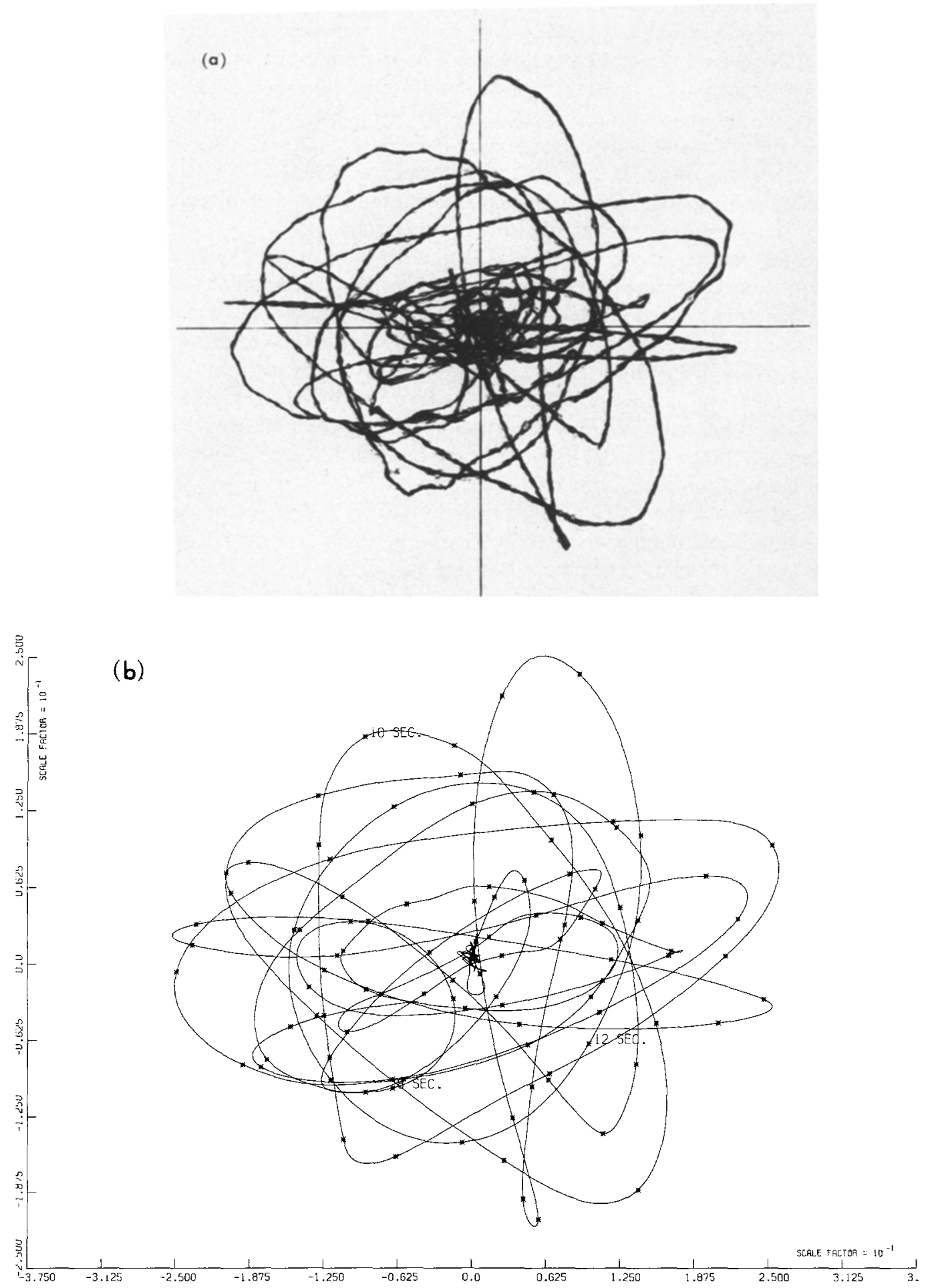

Fig. 7. Comparison of calculated versus measured response of Athenaeum seismoscope: (a) measured record, (b) computed behavior. 
Because of the difficulty with the Castaic record, it was decided to abandon objectivity in the case of the Athenaeum calculations. The measured accelerations were, therefore, employed to obtain a calculated seismoscope response for comparison with the actual seismoscope record to insure that both records were complete. The Athenaeum record is shown in Figure 7a, and Figure $7 \mathrm{~b}$ shows the calculated seismoscope response using the measured Athenaeum accelerations. For the sake of clarity, the long, relatively low amplitude tail on the acceleration record was not used in order to avoid obscuring the center of the record. It can be seen from a comparison of Figure 7, a and b, that the correspondence is extremely good, and individual points can be located and matched from record to record. When this had been established, the disentanglement of the Athenaeum record proceeded. It proved to be extremely difficult to do because of the small size. With some effort, approximately 3 or $4 \mathrm{sec}$ of record were unraveled for analysis. The analysis proceeded as before except that some stretches of the record proved difficult to smooth by hand because of the small amplitude of the high-frequency timing oscillation. This renders interpretation of certain parts of the record questionable, but this was, of course, known at the time of the analysis. When the record had been disentangled, digitized, smoothed and redigitized at equal time intervals, the calculation of the acceleration history proceeded. For the Athenaeum seismoscope, the timing frequency was measured by vibration test to be $17.0 \mathrm{~Hz}$. In this case, relative velocity response spectra of the calculated accelerations in the north and east directions were also computed for the portion of the record evaluated and for comparison with the spectrum of the same portion of record obtained from the measured accelerations.

\section{RESULTS}

In Figure $8 \mathrm{a}$ are shown the resulting calculated north and east components of the Athenaeum accelerations for comparison with Figure $8 \mathrm{~b}$, which is the measured accelerations over the same time interval. It can be seen that there is a reasonable correspondence between large portions of the two records, although one or two spikes shown at points $\mathrm{A}$ and $B$ in the calculated accelerations do not appear on the measured ones. A detailed comparison of the accelerations with the portions of the seismoscope record from which they were derived shows that the spikes were obtained in sections of record in which the high-frequency timing oscillations were of low amplitude and were not clear and distinct. The difficulty, therefore, arises from spurious interpretations of these oscillations. The comparison shows that where the timing marks were clear and had a good amplitude, the interpreted accelerations correspond quite closely to those measured. Although for simulation purposes, or other calculations, the calculated accelerations are important, it is of more general engineering interest to compare the resulting relative velocity response spectra for the calculated and measured accelerations. These spectra are shown in Figure 9a for the calculated accelerations and in Figure 9b for the measured Athenaeum accelerations. It can be seen, first of all, that there is a correspondence between the amplitudes of the two spectra and that the general characteristics of the spectra are similar. It should be emphasized here that the spectra shown are not the spectra of the entire Athenaeum record, but only of the portion analyzed.

Although it was the best record that could be obtained for the purpose of analysis, the Athenaeum record is obviously not an ideal one on which to base estimates of the validity of this analysis procedure. In contrast, the abutment record in particular exhibits clearly marked high-frequency oscillations all over the unraveled portion, and there are only a few places on the record where the amplitude of the high-frequency waves is small. In general, the analysis of the abutment record is expected to have a greater fidelity to the accelerations that occurred there than that of the Athenaeum seismoscope. The abutment 
㸃

(a)

宛

$\sum_{\square}^{\infty}$

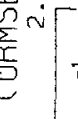

जิํㅇㅁ

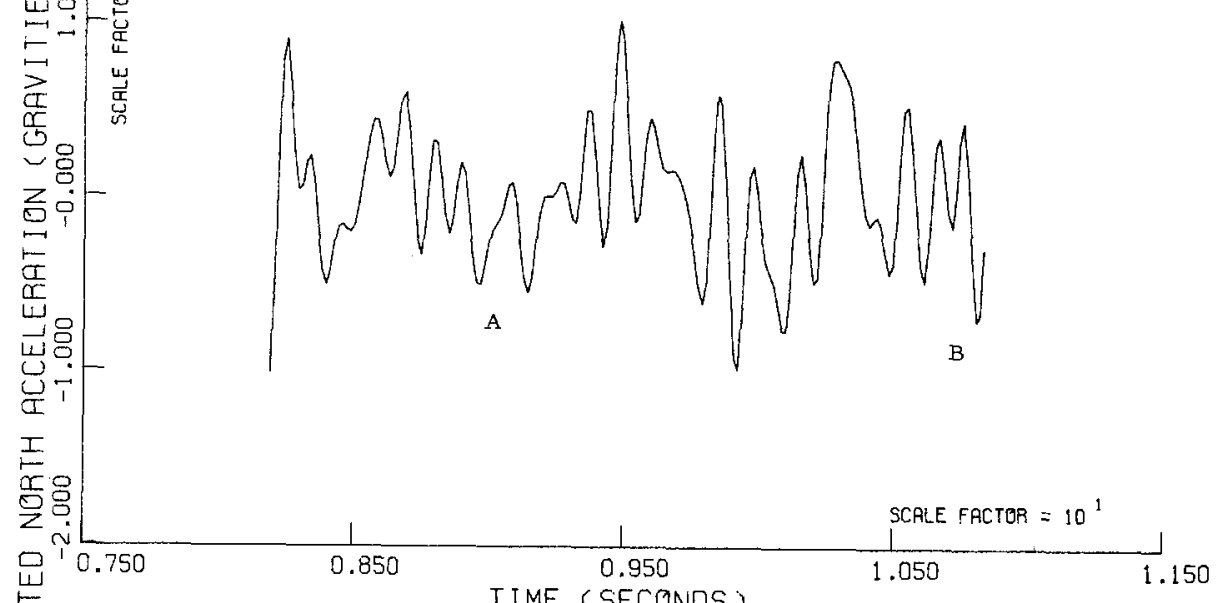

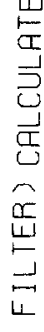

品

T

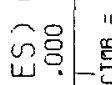

=-

竞 㟧

苍星

$2 \dot{0}$

缺

너요.

号

它品

문 0.750

孚

TIME (SECONDS) 1.150

$\overline{\overrightarrow{5}}$

苛 
(b)
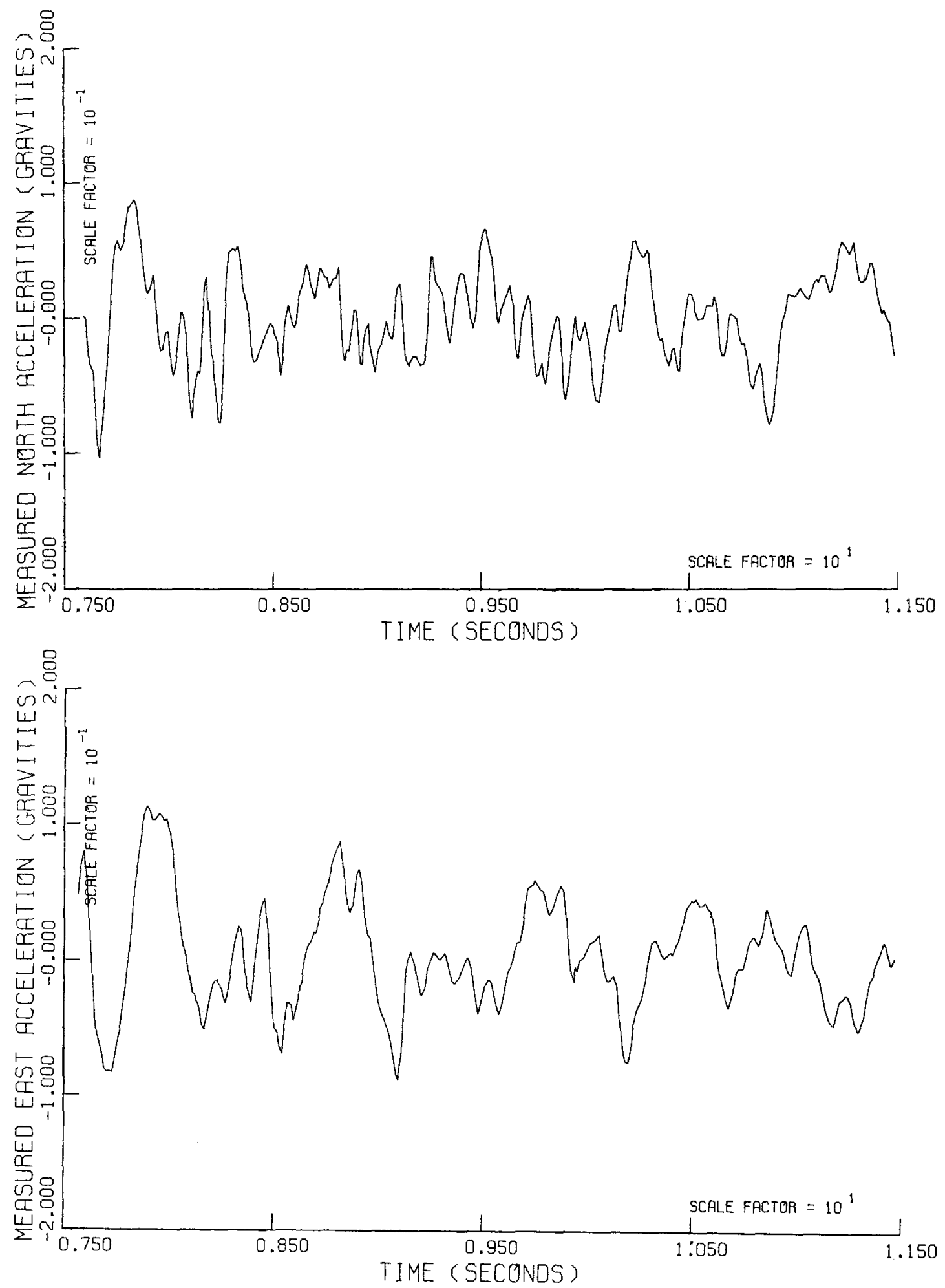

FIG. 8. Comparison of measured Athenaeum accelerations with accelerations computed from seismoscope response; (a) computed acceleration components, (b) measured acceleration components. 
analysis should be everywhere at least as good as the best portion of the Athanaeum comparison.

The calculated San Fernando dam abutment accelerations in the directions perpendicular to and parallel to the axis, as obtained from the analysis of the seismoscope record, are shown in Figure 10a. The calculated accelerations in the north and east directions, as well as the velocities and displacements by integration of these records are given in Figure
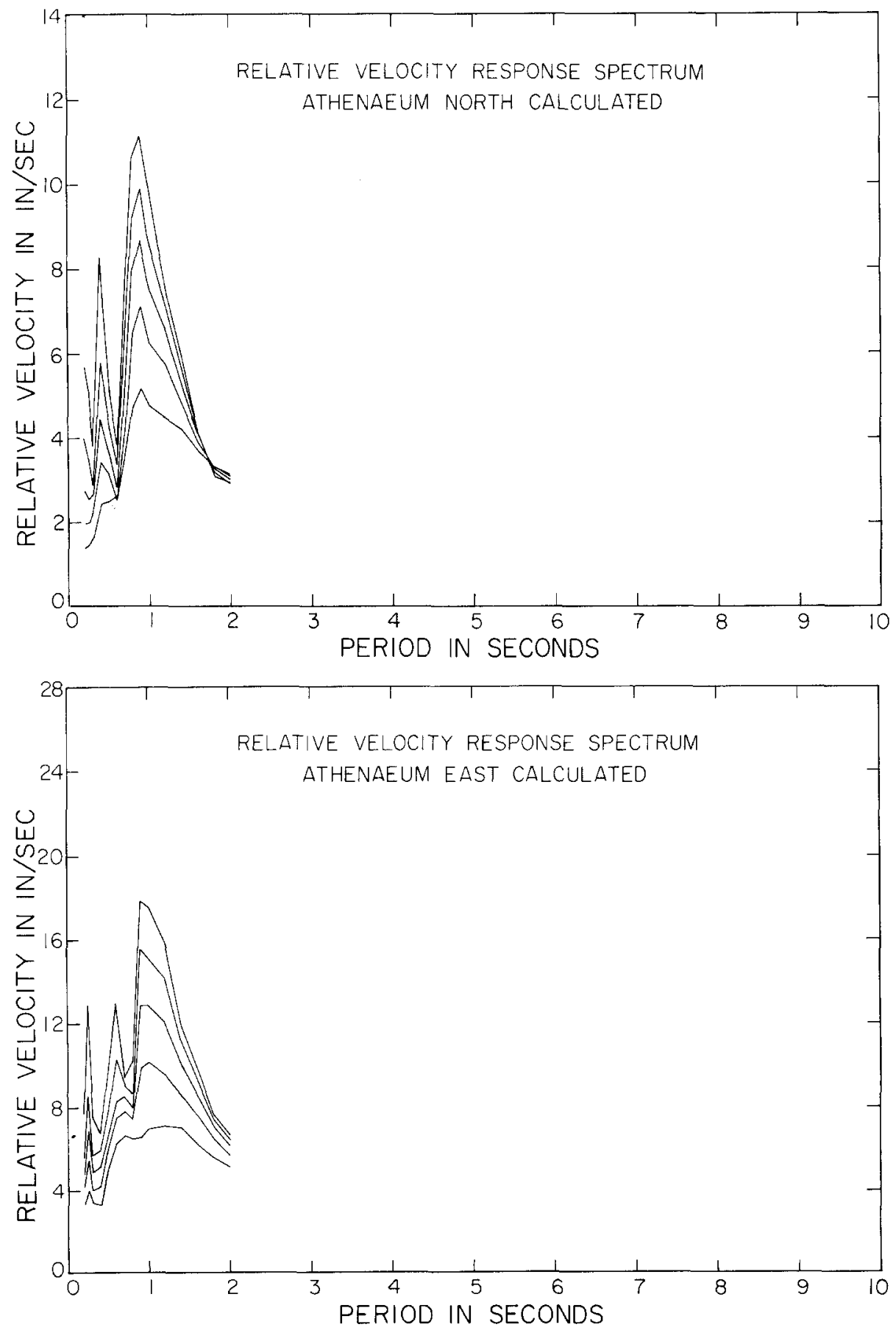

FIG. 9. Comparison of relative velocity-response spectra for Athenaeum accelerations, (a) response spectra from computed accelerations. 
$10 \mathrm{~b}$. On the plots, up represents a positive acceleration toward the north and east directions, respectively, in contrast to the usual convention in acceleration records. Some discussion of these records is of interest. It will be noticed first that on Figure $4 \mathrm{~b}$, the needle appears to go off the watch glass at two locations, A and D. In point of fact, an
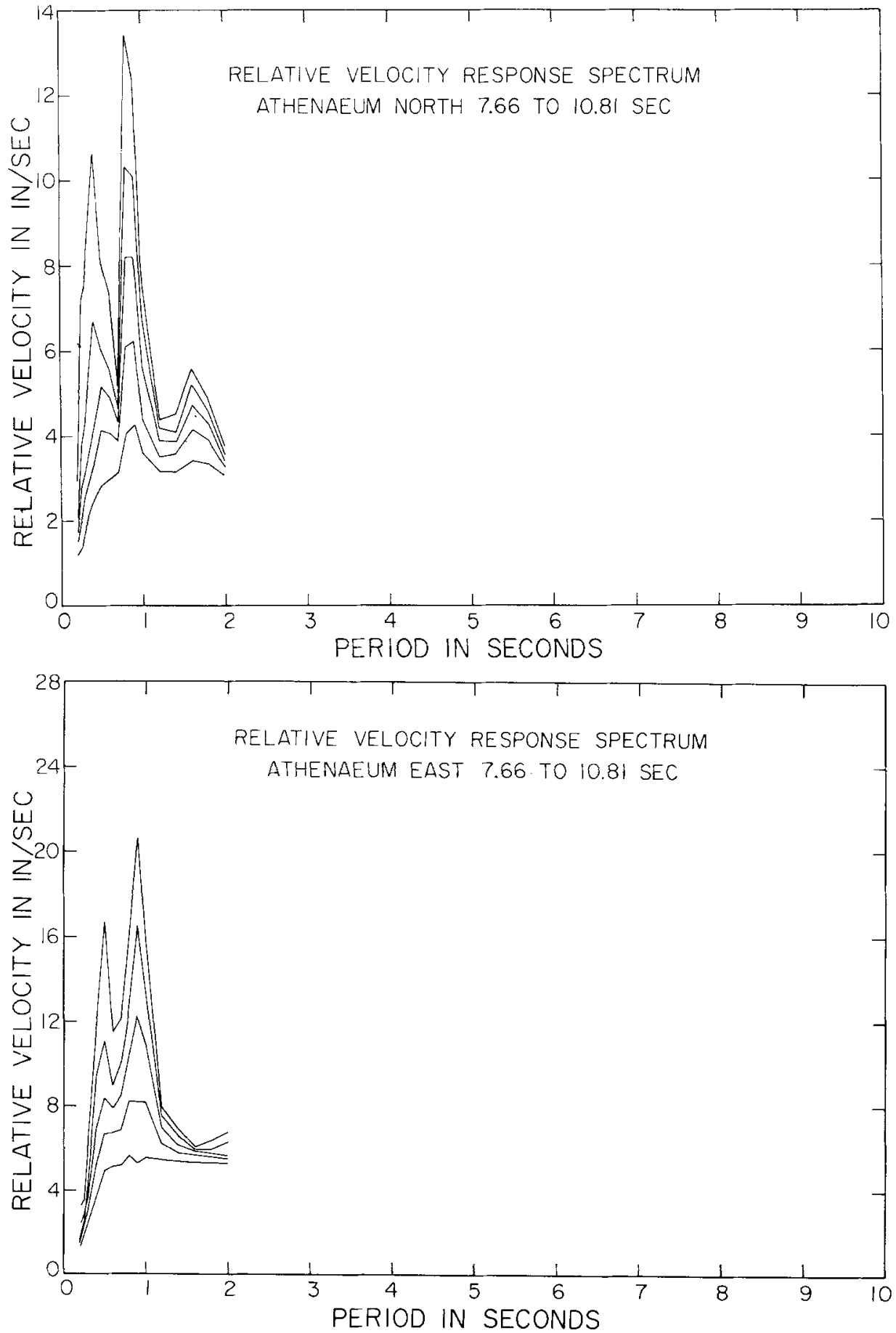

FIG. 9. (b) Response spectra from measured accelerations. 
examination of the seismoscope on which the recording was made indicates that it is not possible for the pen to go off the glass at point A; instead the pendulum of the seismoscope comes up against a stop before the needle reaches the edge of the glass. At point A, therefore, the pendulum hit a stop, and the needle jumped in consequence, without going
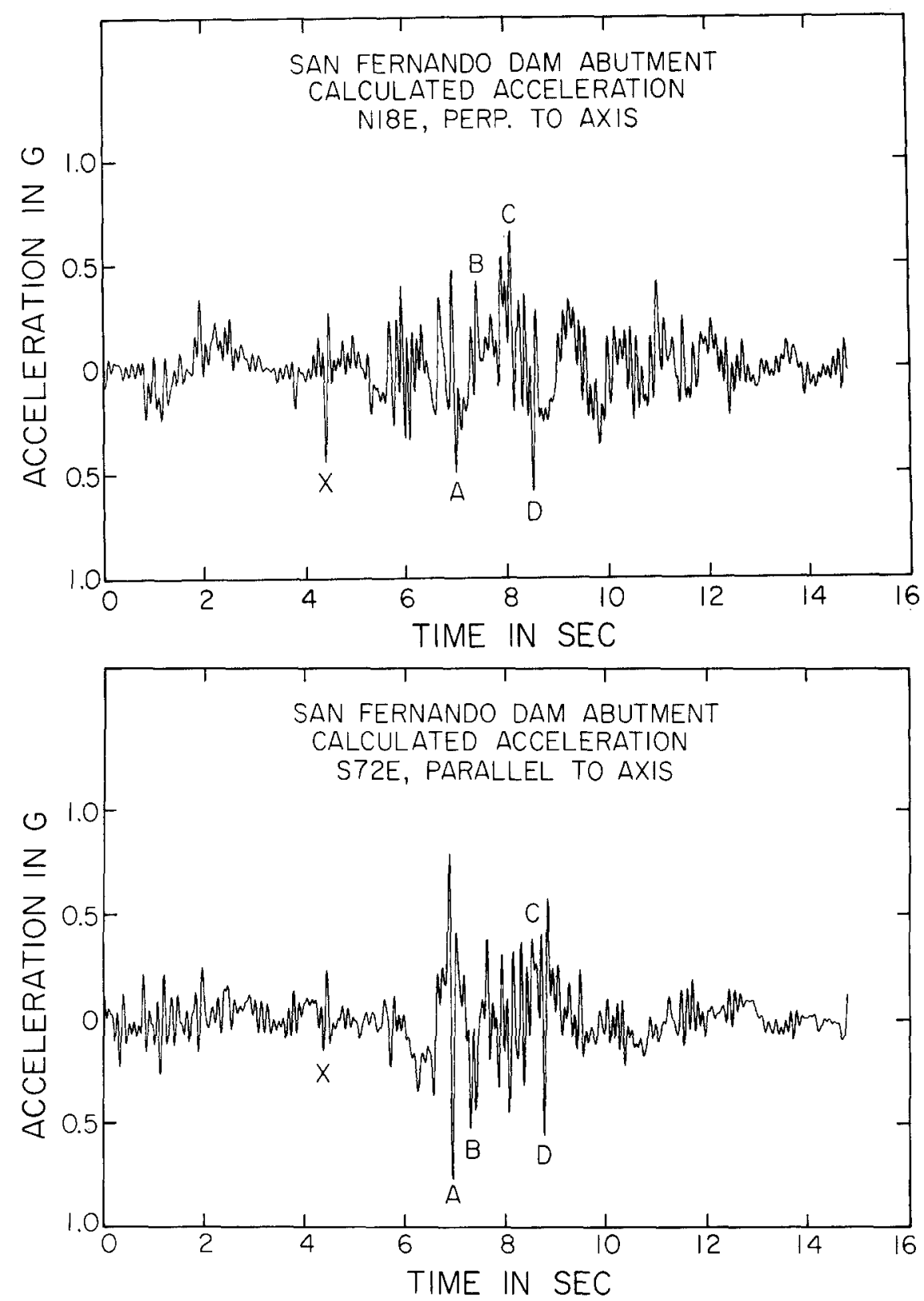

FiG. 10a

FIG. 10. Acceleration components calculated fromseismoscope record S-213.

over the edge of the glass. Although it can be seen in Figure $4 \mathrm{~b}$ that there are highfrequency oscillations prior to the event at $A$, it can be noticed that they are much larger after point $\mathrm{A}$; this mode of vibration of the instrument was apparently enhanced by the 
impact of the pendulum. Subsequent to the event at A, the record traced by the needle moves eventually to point $\mathrm{D}$, at which the pen apparently did leave the watch glass, since the instrument permits this to occur at this position. Since the trace following re-entry of the pen is not characterized by a large amplitude of high-frequency vibration, it may be deduced that, at $\mathrm{D}$, the pendulum did not make contact with the support. The position of the support permits an extreme value of displacement of the pendulum for this loop to be estimated.
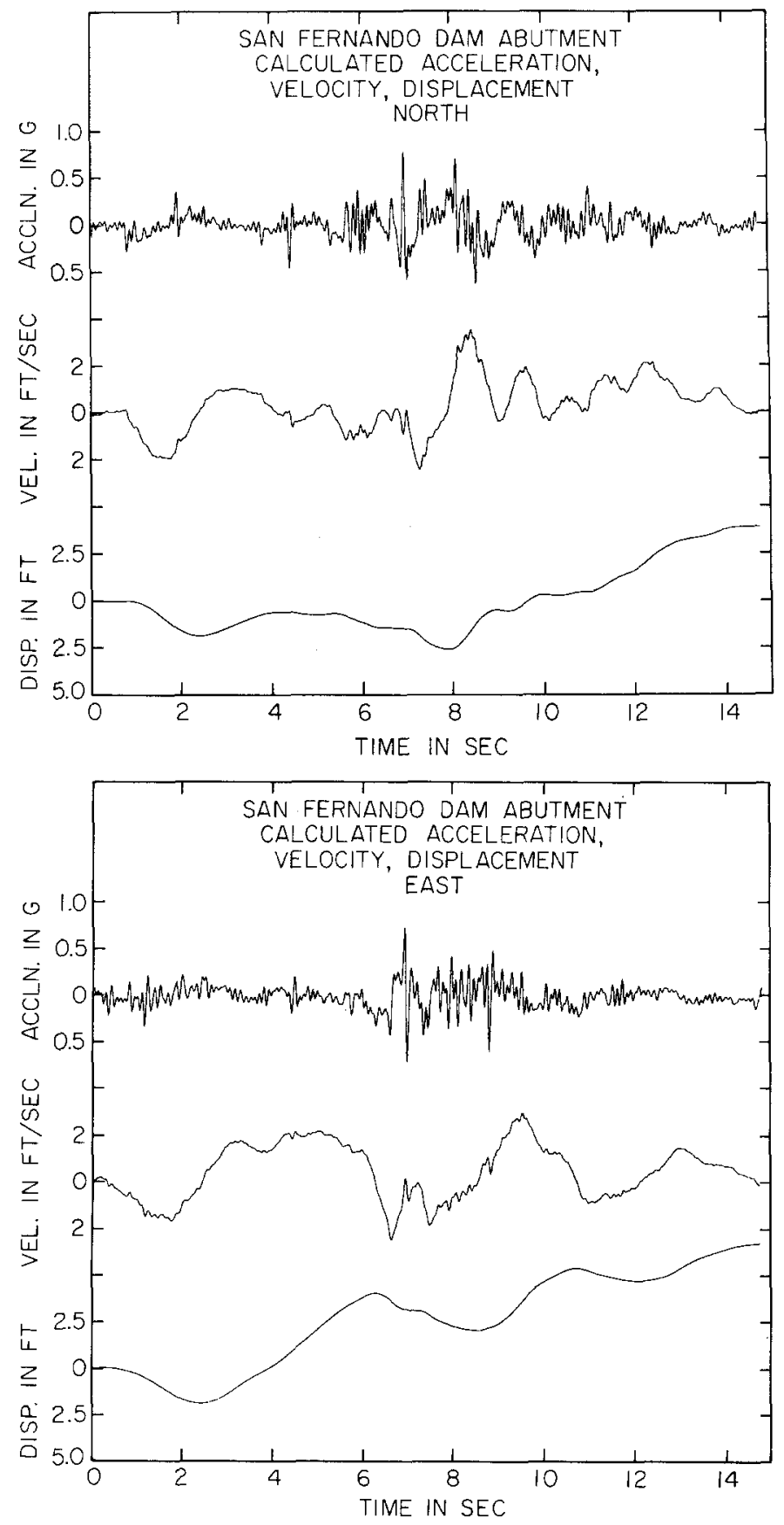

FIG, 10b 
It will also be observed that a peculiar looping of the trace is evident at point $\mathrm{C}$ following shortly after the impact of the seismoscope at point A. Again examination of the instrument indicated that the pendulum contacted the support of the instrument when the needle was in the vicinity of point $C$. In consequence, a careful examination was made of the instrument's behavior with the pen in the position indicated by point $B$ to see if any further contact could have been made with the support there. Although the pendulum must have been very close to contact, it was concluded that, in fact, no impact occurred at point B. All of the other motions of seismoscope S-213 seem to have been genuinely caused by the earthquake.

With these considerations in mind, we can examine the calculated accelerations from seismoscope S-213 as shown in Figure 10. It should be pointed out that a seismoscope undergoes unknown torsional oscillations of substantial amplitude about the suspension wire in the course of its displacement by an earthquake, so that the terms "north" and "east" acceleration should be taken to refer to these component directions only to within an accuracy of perhaps $\pm 10^{\circ}$. On both the north and east components of acceleration, a number of peaks of substantial magnitude in the range 0.6 to $0.8 \mathrm{~g}$ are apparent. Each of the peaks will be discussed in turn.

Peak X, at approximately $5 \mathrm{sec}$, results from a portion of the seismoscope record where it is extremely difficult to tell if the disentangling has proceeded correctly. From this, and its magnitude, it seems fair to assume that the peak is spurious, since a different interpretation of the direction of the trace would give a different result at this place. The peak shown in the north acceleration record at point A occurs where the pendulum strikes the support at point $A$ in Figure $4 \mathrm{~b}$. Since the trace cannot be interpreted beyond the point where it vanishes, an interpolated trace was substituted for continuity. The peak at this point is therefore artificial, but may reasonably represent the acceleration due to the impact of the pendulum. Different interpretations of the record would give higher or smaller values of acceleration at this point. The peak at point $C$ corresponds to point $C$ on Figure $4 b$, and is therefore attributable to the acceleration which occurred when the seismoscope pendulum hit the support. The trace, as can be seen on Figure $5 b$, is continuous and different observers might pass a number of smoothly fitting curves through the trace. This has been done and the different interpretations give rise to a number of estimated accelerations due to this impact. That shown in Figure 10 is the smallest acceleration that has been obtained out of several attempts. Here this acceleration may be counted to be real but is not due to the earthquake, and thus should not be included in an analysis using these calculated accelerations.

The peak accelerations shown at points $\mathrm{D}$ on both acceleration records occur where the seismoscope pen left the glass plate at point $\mathrm{D}$ in Figure $4 \mathrm{~b}$. Once again, these accelerations are spurious since they were obtained from a plausible, but not necessarily correct, trace that was fitted through the recorded data. They may, however, be in the right range of magnitude. All other peaks which appear on the record and are not discussed above result from continuous visible portions of the seismoscope trace; their interpretation has been examined on the original record in considerable detail. For example, the peak at $8 \mathrm{sec}$ on both records is real to the best judgment that can be exercised at this time.

It would appear that peak earthquake accelerations of perhaps 0.55 to $0.6 \mathrm{~g}$ on this filtered $(10 \mathrm{~Hz})$ record might reasonably have been obtained at points $A$ and $D$ if the pendulum had been unrestrained, since visible portions of the record of considerably less amplitude give rise to values of about $0.5 \mathrm{~g}$. It is suggested, therefore, that a reasonably accurate representation of the strong-motion accelerations occurring at the east abutment of the dam can be obtained by using the calculated accelerations shown in Figure 10, but in which the largest peaks are truncated to, say, $0.6 \mathrm{~g}$. A slight difference in these values has little effect in the analysis of a structure with a natural frequency lower than 

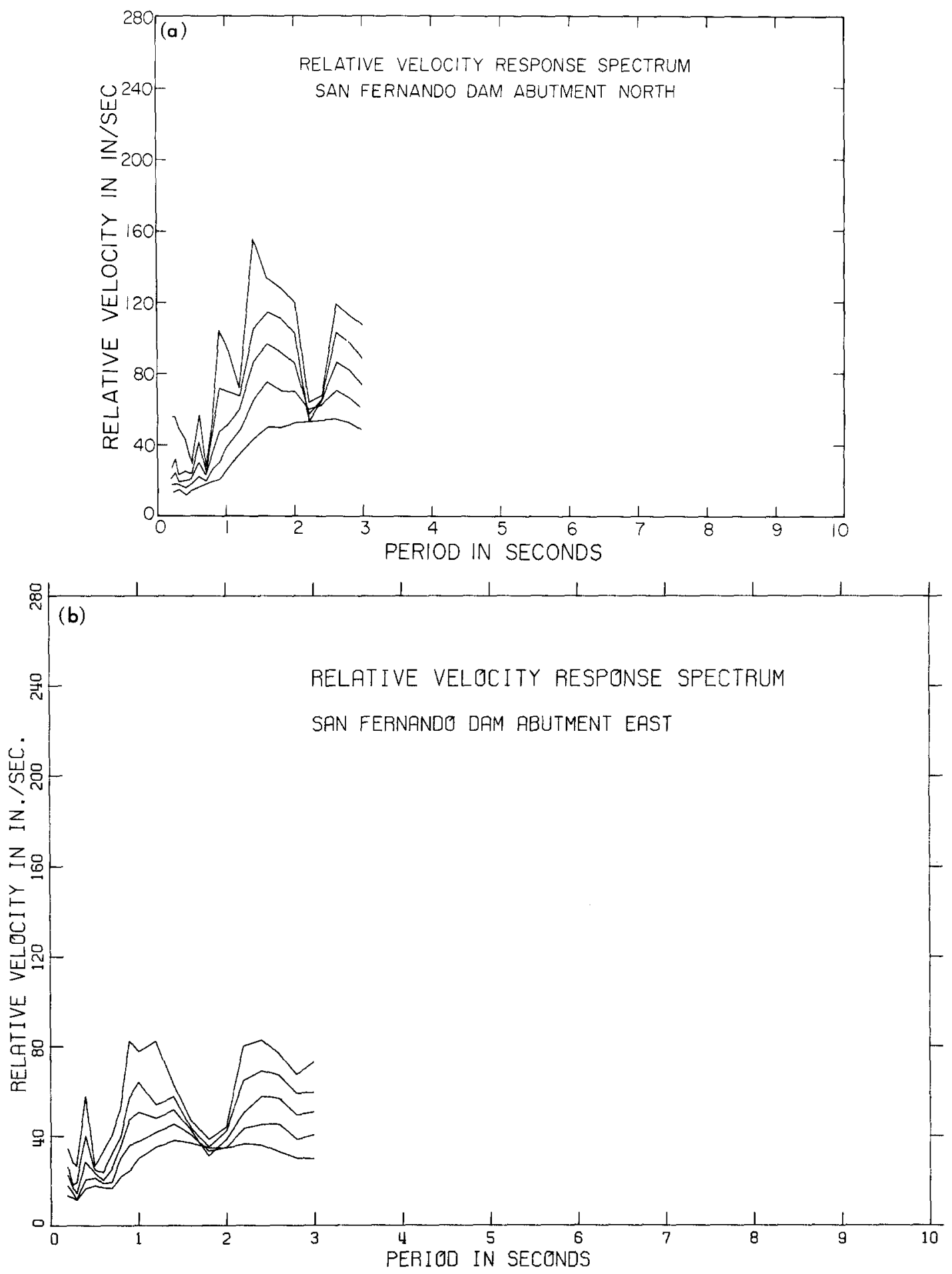

Fig. 11. Relative velocity-response spectra for computed acceleration components, seismoscope S-213 
$10 \mathrm{~Hz}$. The relative velocity response spectra produced from the accelerations are likewise largely unaffected.

The spectra are shown in Figure 11 for the two components of earthquake motion. It is seen that the north component gives the bigger spectral values. The values of relative velocity response spectrum at periods of $0.75 \mathrm{sec}$ and 7 to 8 per cent damping corresponding to the seismoscope conditions are about $2 \mathrm{fps}$ as indicated in the earlier paper (Jennings, 1971). In Figure 12, the relative velocity response curves at 10 per cent damping, averaged from the two horizontal components, are shown to the same scale for the Pacoima dam accelerations, Holiday Inn accelerations, and those from Figure 11.

The accelerations shown in Figure 10 were integrated twice to give velocity and displacement as a function of time, respectively. These results, as well as the spectrum shown in Figure 11, indicate that components of about 3- and 5-sec periods are strongly

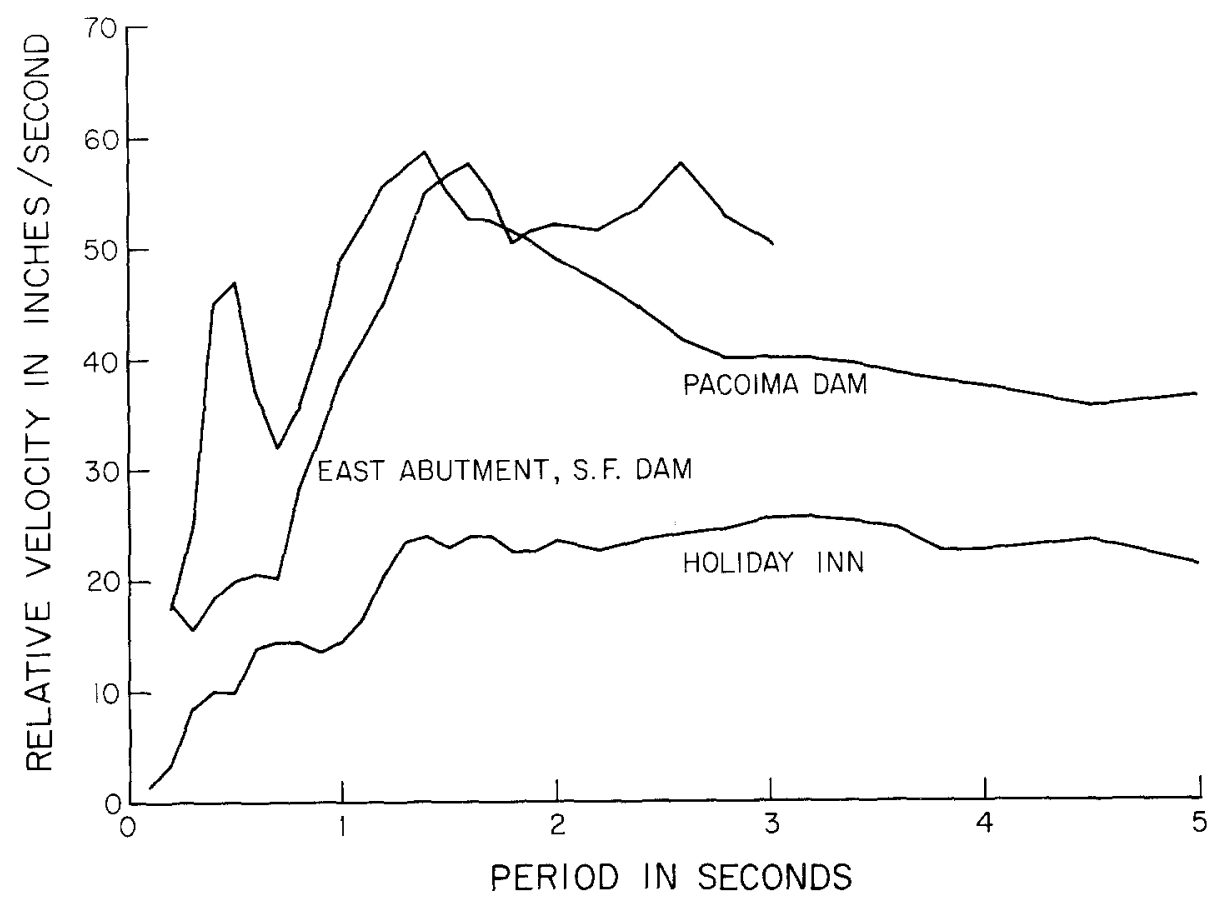

FIG. 12. Comparison of relative velocity-response spectra.

evident in the shaking. The approximate analysis described above indicates that these vibrations are real, and are not a function of the method of obtaining the accelerations. The long-period vibrations may either be part of the general ground shaking at this site or may be a local consequence of the vibrations of the dam closely adjacent to the abutment seismoscope site. If it proves possible to analyze and interpret the record obtained on the crest of the dam (Figure 4a) over a sufficient length of time, the latter hypothesis may be tested. The integrations of the acceleration records give an estimate of the margin of error involved in locating the central point of the seismoscope record in Figure $4 \mathrm{~b}$. The results indicate that the central point was placed on the original record approximately 0.006 in too far to the east, and about 0.04 in too far to the south. The greater error in the north-south direction could also result from either a real ground movement in this orientation, in part, or from a tilt of less that $1^{\circ}$ toward the south, during the earthquake. 
Unfortunately, the leveling of the seismoscope is not carried out with sufficient precision to determine whether the latter is possible.

\section{CONCLUSIONS AND ReCOMmENDATIONS}

A fortuitous combination of circumstances which caused a timing mark to be placed on a seismoscope record enabled the record to be analyzed to give the input acceleration components. From an examination of the San Fernando dam abutment record S-213 and its analysis, it is considered that the calculated accelerations given in this paper are sufficiently representative of the real site motions for employment in further computations, such as analysis of the dam failure.

A scrutiny of a number of seismoscope records indicates that the high-frequency oscillations have occurred at a number of other locations and, in fact, appear somewhere on nearly all recorded seismoscope traces. However, their amplitude is frequently not large enough to enable the simple hand-smoothing techniques described in this paper to be applied. It is possible that more sophisticated techniques of examining the curves by means of computer analysis may prove fruitful. If this can be carried out in some formalized manner, then seismoscope records will constitute a valuable resource not only of spectrum values, but of actual acceleration determinations in past and future earthquakes. Unraveling the record is likely to remain a problem.

The seismoscope is such a simple and inexpensive device that it would be very valuable to extend its capabilities in the direction suggested by the present analysis. It is therefore suggested that some consideration be given to modifications in the design of the seismoscope as follows:

1. It is unfortunate that in this earthquake the glass plate was thrown off two of the seismoscopes which would have been very interesting to analyze, Pacoima dam and Dry Canyon Reservoir (main dam crest). The attachment of the watch glass to the pendulum should be strengthened to prevent this. It is extremely fortunate that both the San Fernando dam seismoscopes retained the glass plates throughout the motion.

2. The recording pen went off the edge of the glass plate on a number of seismoscopes, where, in addition, the pendulum impinged on the supporting structure. It is advisable to increase the diameter of the watch glass, possibly by making the recording surface of a plastic material, and to alter the design of the pendulum and supports so that larger swings can be accommodated.

3. It is desirable to investigate the possibility of ensuring that the timing oscillations, or some substitute, are induced during an earthquake. The present frequency (15$18 \mathrm{~Hz}$ ) or even higher is suitable for analysis purposes.

4. The seismoscope base should include calibrated leveling bubbles and screws, so that the device can be made level to a precision of about $10 \mathrm{~min}$ of arc. Periodic checks of the level should be made, and the post-earthquake attitude should be read when the record plate is removed.

5. A method of locating the pre-earthquake stationary position of the pen on the watch glass to within approximately \pm 0.002 in would be very desirable, since it is very hard to determine this point after pendulum motions have taken place. This point was noted previously by Hudson and Cloud (1967).

The February 9 San Fernando earthquake (Hudson, 1971) produced a number of seismoscope records of which parts appear to be suitable for analysis by the method of this paper. They are given in Table 1. 


\section{TABLE 1}

SeIsmoscope Records Suitable for ANalysis

By the Method of THIS Paper

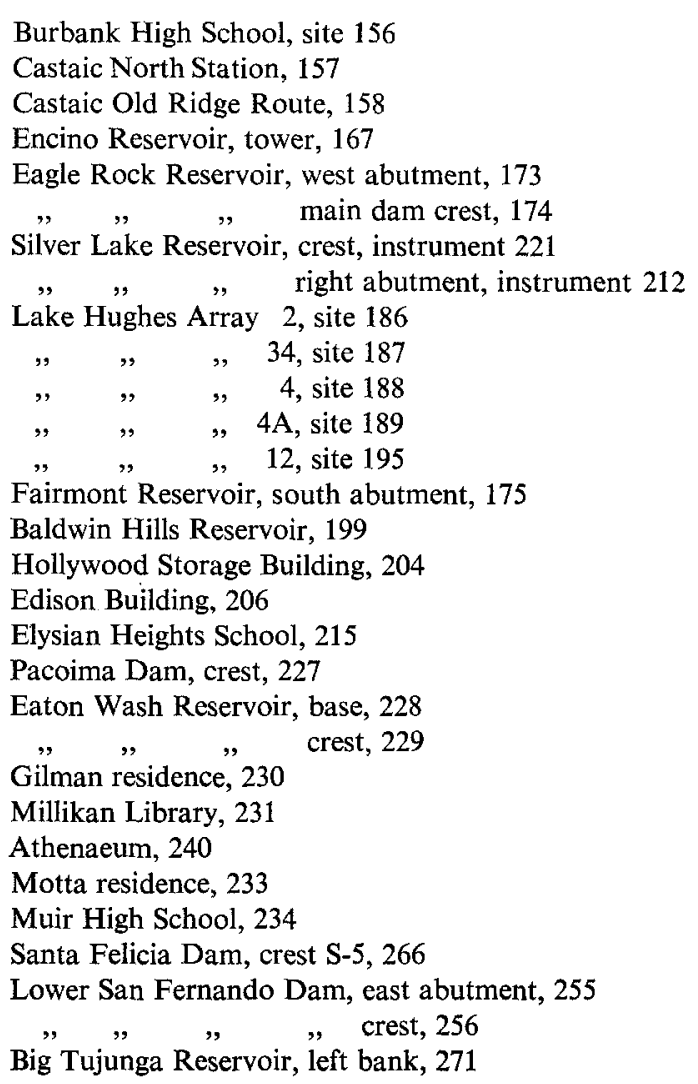

\section{ACKNOWLEDGMENTS}

The previous experience of Dr. M. D. Trifunac of the California Institute of Technology in analyzing seismoscope records was invaluable to this work. Dr. Trifunac was most helpful in many discussions of the analysis and filtering of the data and, in addition, made his seismoscope computer program available to check the results. The compilation of new computer programs and the incorporation of previous ones into the computational procedure was carried out with extreme competence by D. R. Putnick, graduate student, now at the University of Wisconsin. Dr. A. G. Brady was very patient in many explanations of digitizing and computational processes and errors. The enthusiasm and encouragement of Dr. D. E. Hudson is gratefully acknowledged.

The work was carried out with the assistance of National Science Foundation Grant GI-29937.

\section{REFERENCES}

Cloud, W. K. and D. E. Hudson (1961). A simplified instrument for recording strong-motion earthquakes, Bull. Seism. Soc. Am.51, 159-174.

Lanczos, C. (1961). Applied Analysis, Prentice-Hall, New Jersey.

Ormsby, J. F. A. (1961). Design of numerical filters with application to missile data processing, J. Assoc. Computing Mach. 8, 440-466.

Hudson, D. E. and W. K. Cloud (1967). An analysis of seismoscope data from the Parkfield earthquake of June 27, 1966, Bull. Seism. Soc. Am. 57, 1143-1159. 
Cloud, W. K. and D. E. Hudson (1968). Strong-motion instrumental data on the Borrego Mountain earthquake of April 9, 1968, Earthquake Engineering Research Laboratory, Calif. Inst. of Tech., and Seism. Field Survey, NOAA, U.S. Dept. of Commerce, August.

Trifunac, M. D. and D. E. Hudson (1970). Analysis of the Station No. 2 seismoscope record-1966, Parkfield, California earthquake, Bull. Seism. Soc. Am. 60, 785-794.

Hudson, D. E., Editor (1971). Strong motion instrumental data on the San Fernando earthquake of February 9, 1971. Earthquake Engineering Research Laboratory, Calif. Inst. Tech., and Seism. Field Survey, NOAA, U.S. Dept. of Commerce, September.

Jennings, P. C., Editor (1971). Engineering features of the San Fernando earthquake, Earthquake Engineering Laboratory, Calif. Inst. of Tech., EERL 71-02, June.

Division of Engineering and ApPlied Science

CALifornia Institute or TeChNology

Pasadena, California 91109

Manuscript received February 22, 1973. 